\title{
Investigation on physical properties of patia clay (Chittagong), Bangladesh
}

\author{
A. H. Dewan ${ }^{1}$, S. Mustafi ${ }^{1}$, M. Ahsan ${ }^{1}$ and M. S. Ullah ${ }^{2}$ \\ ${ }^{1}$ Institute of Glass and Ceramic Research and Testing (IGCRT), Bangladesh Council of Scientific and Industrial \\ Research (BCSIR), Dhaka. \\ ${ }^{2}$ Dhaka College, Dhaka.
}

\begin{abstract}
The physical and microstructural characteristics of Patia clay of different areas (Hydgaon-1, Hydgaon-2 and Kanchannagar) were investigated. Patia clays were beneficiated by repeated sedimentation method. The chemical compositions of raw (unwashed) and washed clay was determined. The physical properties of fired Patia clay were measured. Results show that the water absorption values decrease and the firing shrinkage values increase with increasing firing temperatures in all types of Patia clays (raw and washed) of three different areas. The microstructures of Patia clay pronounce that they contain kaolinite, illite and quartz as major phases and mica, gibbsite and hematite are present as minor phases.
\end{abstract}

Key words: Patia clay; Plasticity; Water absorption; Firing shrinkage; XRD and FTIR

\section{Introduction}

Clays and clay minerals form under a fairly limited range of geological conditions. The environments of formation include soil horizons, continental and marine sediments, geothermal fields, volcanic deposits, and weathering rock formations. Most clay minerals form where rocks are in contact with water, air, or steam. Most of the properties are almost common in all clay minerals.

Clays and clay minerals are very important in process industries, agriculture, engineering, construction, geology, environmental, and for other miscellaneous applications (Nugun et.al 2012). They have been widely used as the main raw materials in fabrication of diversified ceramic products for construction materials such as bricks and tiles due to many of their specific properties before and after firing (Lee and Yeh 2008; Mahmoudi et al. 2008). The chemical compositions, particle size distribution and mineral composition of clay minerals have been reported to influence their ceramic properties (Bender et al. 1982; Malaiskiene et al. 2011). The main function of clay is to increase the plasticity and drying strength. Clay acts as a flux at high temperatures, its aids vitrification (Alim and Shamin1964). Depending on composition and various other technical characteristics, clay can be processed into different shapes where plasticity, strength and others parameter are varied (Adnan et al. 2011). There has been an increasing interest in utilizing clay minerals such as bentonite, kaolinite, diatomite and fullers earth for their capacity to adsorb not only inorganic but also organic molecules. This naturally occurring material could act as a substitute for activated carbon as an adsorbent due to its availability and low cost and its good sorption properties.

Clay is composed mainly of silica, alumina and water, frequently with appreciable quantities of iron, alkalies and alkali earth (Ralph 1968). Two structural units are involved in the atomic lattices of most clay minerals. One unit consists of closely packed oxygen and hydroxyls in which aluminium, iron and magnesium atoms are embedded in an octahedral combination so that they are equidistant from six oxygen or hydroxyls. The second unit is built of silica tetrahedrons. The silica tetrahedrons are arranged to form a hexagonal network that is repeated indefinitely to form a sheet of composition, $\mathrm{Si}_{4} \mathrm{O}_{6}(\mathrm{OH})_{4}$ (Ralph 1968).

Recently, Bangladesh is exporting ceramic materials in more than 45 countries, including the USA, Italy, Spain, France, New Zealand, Australia and Sweden (Tamjid 2004). The various physical properties such as plasticity, firing shrinkage, water absorption/porosity are dependent on the compositions of used clay.

In this work Patia clay is used as principle ingredient. The name Patia clay is the white burring clay and awaits large scale exploitation by the ceramic, paper and rubber industry of the country. Patia clay occurs abundantly in some particular localities of the district of Chittagong in Bangladesh. The localities are Hydgaon-1, Hydgaon-2 and Kanchannagar respectively. Hydgaon-1 and Hydgaon-2 are situated in 7.0 kilometer and 7.5 kilometer in the East (Patia-Cox's bazar Road) from Patia Upazila (zero point)

*Corresponding author: E-mail: dewan31@yahoo.com 
respectively. Kanchannagar bus stand may be in 5.5 kilometer in the East (Patia-Cox`s bazar Road) from Patia Upazila (zero point) and Kanchannagar is situated in 5.0 kilometer in the South from Kanchannagar bus stand. These regions are totally hilly area. The clay is deposited in different hills. The area comprises of two formation-Dupitila and Alluvium. The predominant color of Dupitila formation is reddish yellow. Generally the clay is light greyish white to bluish white with light yellow and slightly soapa to feel, massive and soft to medium hard. The total estimated reserves of the Patia clay are about 1844 short tons, assuming 1.5 meter depth. A study was made on the raw (unwashed) and beneficiated (washed clay) of three different deposits of Patia. The aim of the present research is the study on physical properties of raw (unwashed) and washed Patia clay and their firing behavior.

\section{Materials and Methods}

Chemical compositions of Patia clay unwashed and washed collected from different area of Patia were carried out using X-ray Fluorescence Spectrometer (XRF) (PANalytical XRF, Model PW- 2404 X-Ray Spectrometer) and the fired Patia clay sample (unwashed and washed) were subjected to various tests. The water absorption and apparent porosity were determined by Archimedes's immersion technique on keeping the specimens in boiling water for $2 \mathrm{hrs}$. Plasticity indices were measured using Atterberg limits which can be used as a reference for determining the degree of plasticity of green bodies. The firing shrinkage was examined by general method. The phases formed of Patia clay were identified by using PANalytical, X-ray Diffractometer (XRD) (X-pert PRO XRD PW3040). FTIR ((IRPrestige-21, Fourier Transform Infrared Spectrophotometer, Shimadzu) was used to analyze the vibrational spectra of Patia clay. Tests are conducted, as far as possible, according to ASTM specification.

\section{Beneficiation of clay}

The method of beneficiation of the clay was adopted on the principle of washing and elutriation in a slow stream of water (Rolad and Joseph, 1927; Stull and Bole 1923).

Two kilograms of Patia clay lumps were crushed into coarse powder and were allowed to soak under water in a large vessel for about a week. The well- soaked clay on thorough blunging in sufficient water completely disintegrated and the fine clay particles together with heavier particles of impurities formed a thick suspension, which was then transferred gradually to the first vessel of the washing apparatus. The rate of water was so adjusted that the clay suspension was sufficiently dilute and the clay particles were efficiently carried away leaving behind the impurities at the bottom of each vessel and finally washed clay suspension from the last vessel containing about 2-3\% solid materials. The washed clay suspension was sieved through ASTM sieve no-200 before it was finally allow for settle in the settling vessel. The washed clay which settled in the settling vessel was separated from water and initially allowed to dry in the sun and finally in an oven at about $75^{\circ} \mathrm{C}$. This dried clay was labeled as the washed clay sample.

\section{Results and discussion}

Table I. shows the results of the chemical compositions of the three different unwashed (raw) and washed Patia clays. It can be seen from Table I. that all of the unwashed clay contains high percentage of silica and low percentage of Alumina. These high percentage of silica and low percentage of alumina of the clays are not suitable for manufacturing better quality ceramic wares. The raw clays are suitable for manufacturing ordinary pottery. The washed clays contain low percentage of silica and high percentage of alumina compared to unwashed clays (Table I). Table I. also shows that all of the unwashed and washed clays contain small amount of $\mathrm{CaO}, \mathrm{MgO}, \mathrm{Na}_{2} \mathrm{O}$ and $\mathrm{K}_{2} \mathrm{O}$ which acts as fluxes in a ceramic body during firing due to the decrease of free silica during washing of raw clay. The LOI (Loss on ignition) of unwashed Patia clay of three different areas are less than washed clay because of the increase the alumina and a decrease of silica after washing.

Table I. Chemical analysis of unwashed and washed Patia clay

\begin{tabular}{llllllll}
\hline Component & \multicolumn{5}{c}{ Composition (\%) } \\
\hline \multicolumn{5}{c}{ Raw/Unwashed } & \multicolumn{5}{c}{ Washed } \\
\hline $\mathrm{SiO}_{2}$ & 74.80 & 73.85 & 75.35 & 60.85 & 59.67 & 62.10 \\
$\mathrm{Al}_{2} \mathrm{O}_{3}$ & 17.15 & 18.20 & 16.10 & 29.03 & 29.78 & 27.62 \\
$\mathrm{Fe}_{2} \mathrm{O}_{3}$ & 1.71 & 1.42 & 1.83 & 0.63 & 0.58 & 1.02 \\
$\mathrm{CaO}$ & 0.28 & 0.16 & 0.25 & 0.12 & 0.10 & 0.12 \\
$\mathrm{MgO}$ & 0.15 & 0.05 & 0.16 & 0.19 & $\mathrm{Trace}$ & 0.05 \\
$\mathrm{Na}_{2} \mathrm{O}$ & 0.15 & 0.12 & 0.30 & 0.11 & 0.08 & 0.19 \\
$\mathrm{~K}_{2} \mathrm{O}$ & 0.70 & 0.35 & 0.63 & 0.55 & 0.17 & 0.35 \\
$\mathrm{LOI}$ & 5.0 & 5.95 & 4.90 & 8.50 & 9.21 & 8.15 \\
\hline
\end{tabular}

Hy-1= Hydgaon-1, Hy-2= Hydgaon-2, Kan=Kanchannagar 
Table II. Plasticity of unwashed and washed Patia clay

\begin{tabular}{lcl}
\hline Sample No & \multicolumn{2}{c}{ Plasticity (\%) } \\
\hline & Raw/Unwashed & Washed \\
\hline Hydgaon-1 & 31.00 & 36.10 \\
Hydgaon-2 & 32.20 & 37.10 \\
Kanchannagar & 29.00 & 33.60 \\
\hline
\end{tabular}

Table II. shows the plasticity of unwashed and washed Patia clay. The improvement in plasticity due to the washing/beneficiation is evident. The plasticity of both Patia clay unwashed and washed have $31 \%, 32.20 \%, 29 \%$ and $36.1 \%, 37.10 \%, 33.60 \%$ of Hydgaon-1, Hydgaon-2 and Kanchannagar respectively which can be said to possess good plasticity (Huber 1956; Misra 1949; Namara and Dulberg 1958) through some plastic sedimentary china clays may have a value of about 50\% (Huber 1956; Misra 1949; Namara and Dulberg 1958). The plasticity of washed clay is higher than unwashed clay which may be due to the decrease of free silica from unwashed clay after washing. Hydgaon-2 Patia clay has higher plasticity compared to Hydgaon-1 and Kanchannagar. Kanchannagar clay shows the lowest plasticity than that of Hydgaon-1 and Hydgaon-2. These phenomena are due to the presence of the highest amount of silica in Kanchannagar.

\section{Water absorption and firing shrinkage of Patia clay}

Some physical properties such as water absorption and firing shrinkage of unwashed and washed clays are shown in Fig.1 and Fig.2 which are a measure of the degree of vitrification at various temperatures. From these Figs., it is shown that the water absorption values decrease and the firing shrinkage increase with increasing firing temperature which indicate that the vitrification characteristics is improved in washed clay than that of unwashed clays. The firing behavior of different kaolins varies widely (Misra and Hummel 1949, Klinefelter et al., 1933, Klinefelter and Meyer 1935), depending upon the mineralogical compositions.
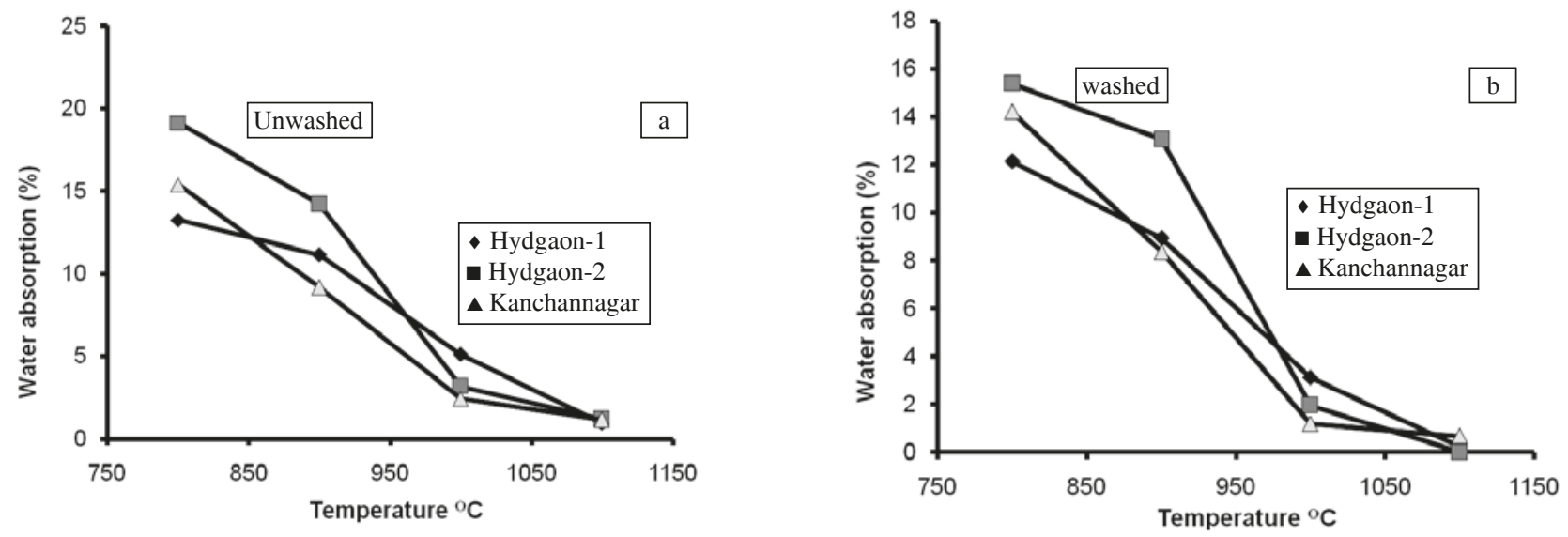

Fig. 1. Water absorption vs temperture of three different (a)unwashed and (b)washed Patia clay
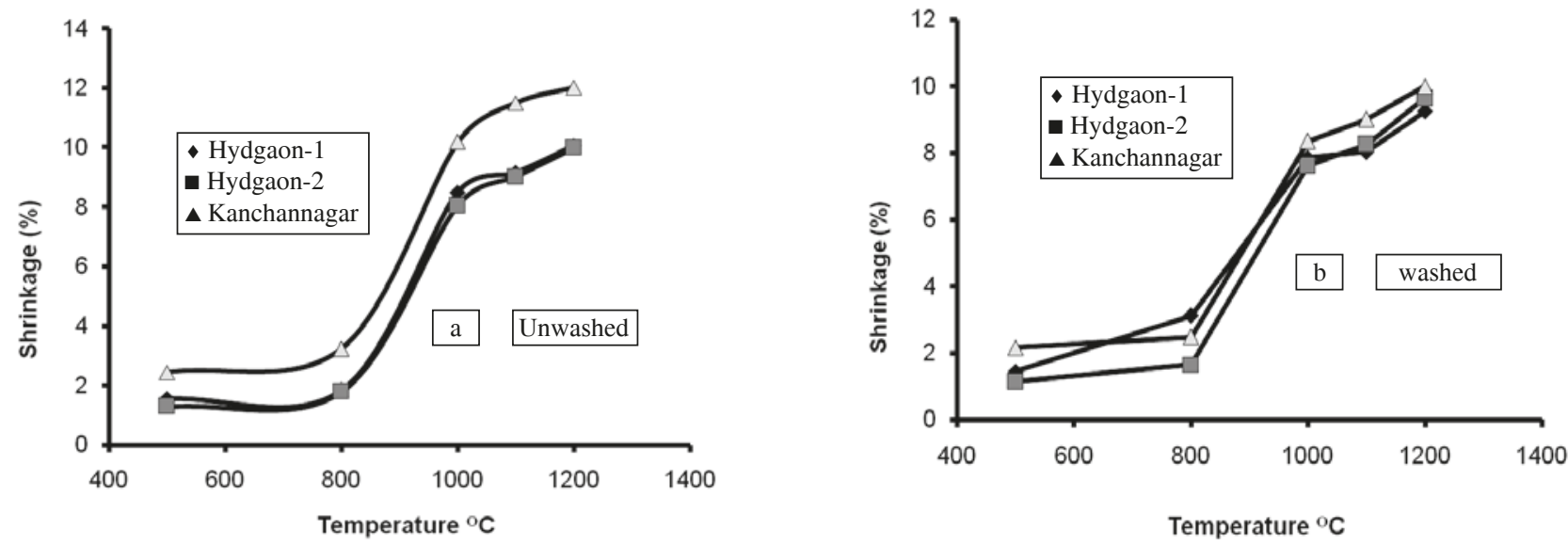

Fig. 2. Shrinkage vs temperature of three different (a)unwashed and (b)washed Patia clay 
Table III. Correct band intensities of unwashed and washed Patia clay

\begin{tabular}{|c|c|c|c|c|c|c|}
\hline Bands & $\begin{array}{l}\text { Hy-1 (raw) } \\
\text { Intensity }\end{array}$ & $\begin{array}{l}\text { Hy-1 (washed) } \\
\text { Intensity }\end{array}$ & $\begin{array}{l}\text { Hy-2 (raw) } \\
\text { Intensity }\end{array}$ & $\begin{array}{l}\text { Hy-2 (washed) } \\
\text { Intensity }\end{array}$ & $\begin{array}{l}\text { Kan (raw) } \\
\text { Intensity }\end{array}$ & $\begin{array}{c}\text { Kan (washed) } \\
\text { Intensity }\end{array}$ \\
\hline 428.2 & 5.25 & 9.08 & 2.53 & 10.95 & 8.48 & 10.05 \\
\hline 470.6 & 15.30 & 22.81 & 9.61 & 26.06 & 20.06 & 23.42 \\
\hline 538.1 & 19.34 & 29.52 & 11.06 & 34.0 & 26.32 & 30.72 \\
\hline 694.3 & 4.85 & 7.05 & 2.56 & 9.66 & 7.09 & 8.36 \\
\hline 781.1 & 6.71 & 3.55 & 4.51 & 4.65 & 2.88 & - \\
\hline 914.2 & 11.12 & 19.08 & 3.78 & 22.73 & 17.90 & 20.30 \\
\hline 1031.4 & 8.28 & 11.03 & 5.75 & 10.39 & 10.04 & 12.78 \\
\hline 1107.1 & 6.22 & 10.05 & 3.06 & 11.98 & 8.81 & 12.05 \\
\hline 1319.3 & 4.31 & 3.21 & 3.84 & 3.63 & 2.43 & - \\
\hline 1627.9 & 0.65 & 8.90 & 0.62 & 10.57 & 6.14 & 7.67 \\
\hline 3441.0 & 0.31 & 6.32 & 0.34 & 7.84 & 0.12 & 0.35 \\
\hline 3620.3 & 6.76 & 9.72 & 3.96 & 11.72 & 9.05 & 9.64 \\
\hline 3693.6 & 10.39 & 14.21 & 5.94 & 17.14 & 12.91 & 14.61 \\
\hline
\end{tabular}

Raw= unwashed, Hy-1= Hydgaon-1, Hy-2= Hydgaon-2, Kan=Kanchannagar

Characterization of Patia clay by XRD and FTIR

Figs. 3-8 show the mineralogical analysis of unwashed and washed Patia clay (Hydgaon-1, Hydgaon-2 and Kanchannagar). From these Figures it is observed that kaolinite and quartz are common major phases and illite, mica and gibbsite are common minor phases present in unwashed and washed of all types of Patia clay. The Hydgaon-1 and Hydgaon-2 both unwashed and washed clay contain the feldspar phase. The hematite phases are present in both unwashed and washed Kanchannagar clay and in only unwashed Hydgaon-1. It is also clear from Figs. 3-8 that the intensity of kaolinite, mica and illite increases in all types of washed Patia clay which is due to the removal of free silica and other impurities from unwashed clay during beneficiation.

From FTIR analysis of three different types unwashed and washed Patia clay, it is shown that all types of clays show approximately similar absorbent bands but the intensity of vibration bands increase in washed clay because of the removal of various types of impurities during beneficiation (Table III).

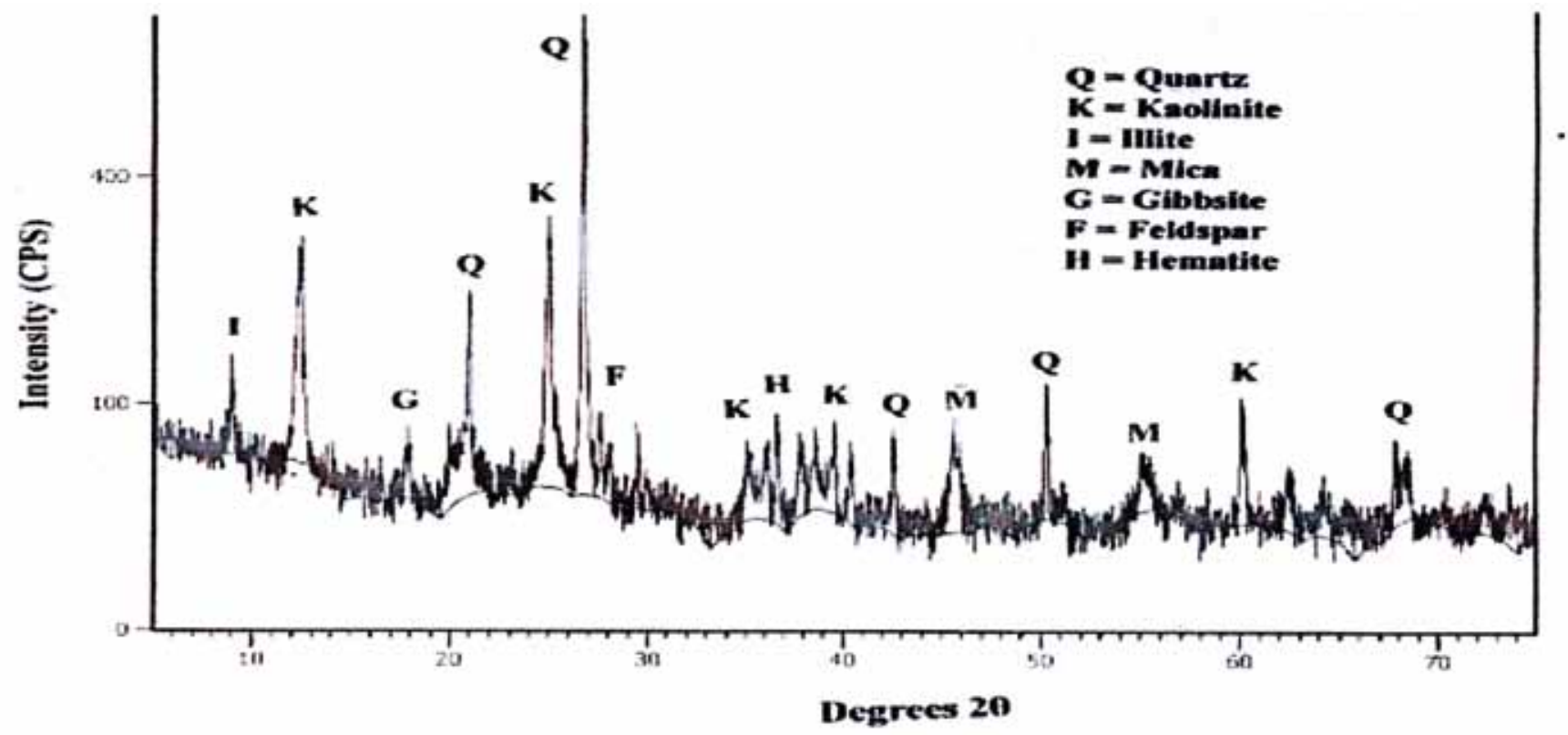

Fig. 3. XRD diffractogram of Hydgaon-1(unwashed) 


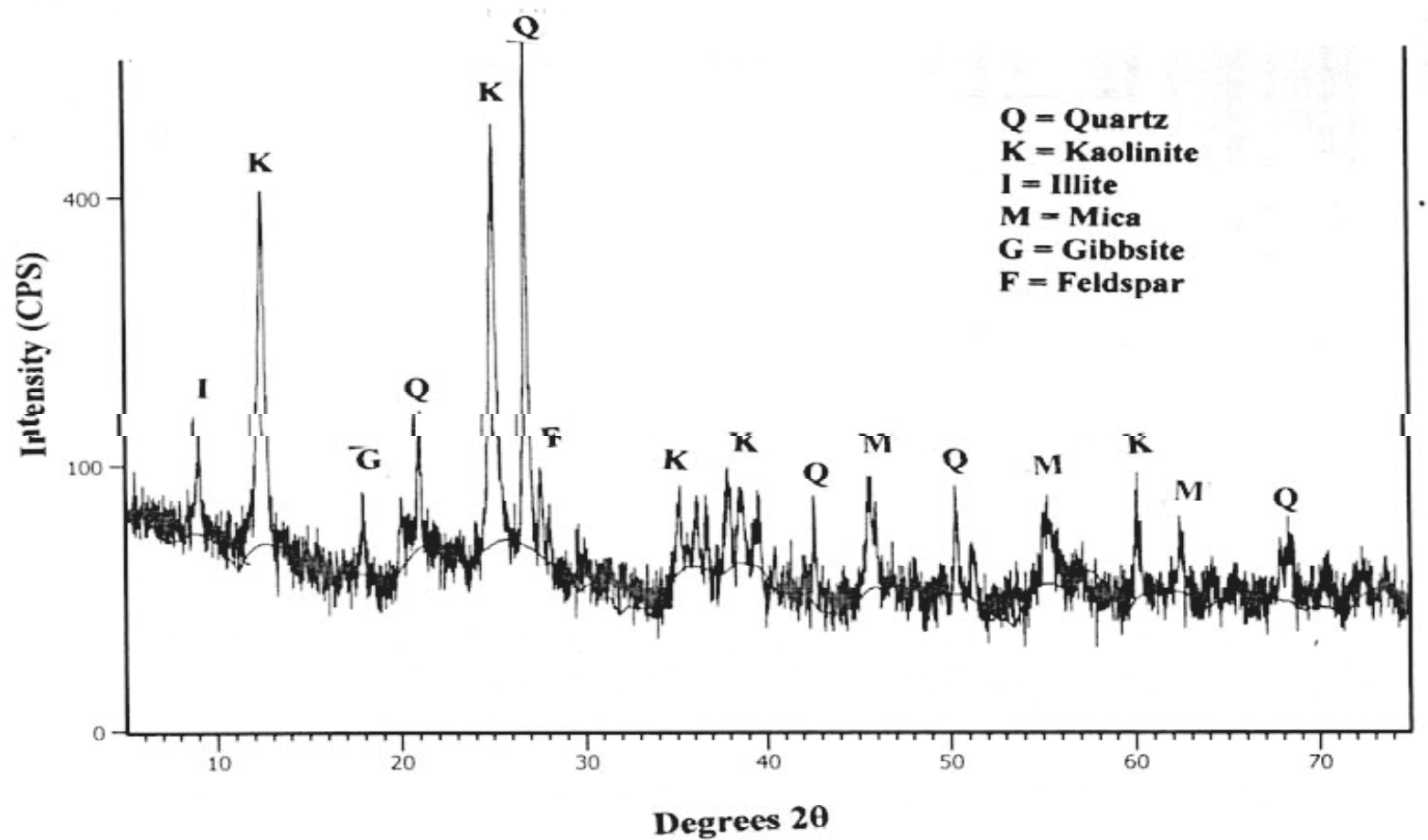

Fig. 4. XRD diffractogram of Hydgaon-1(washed)

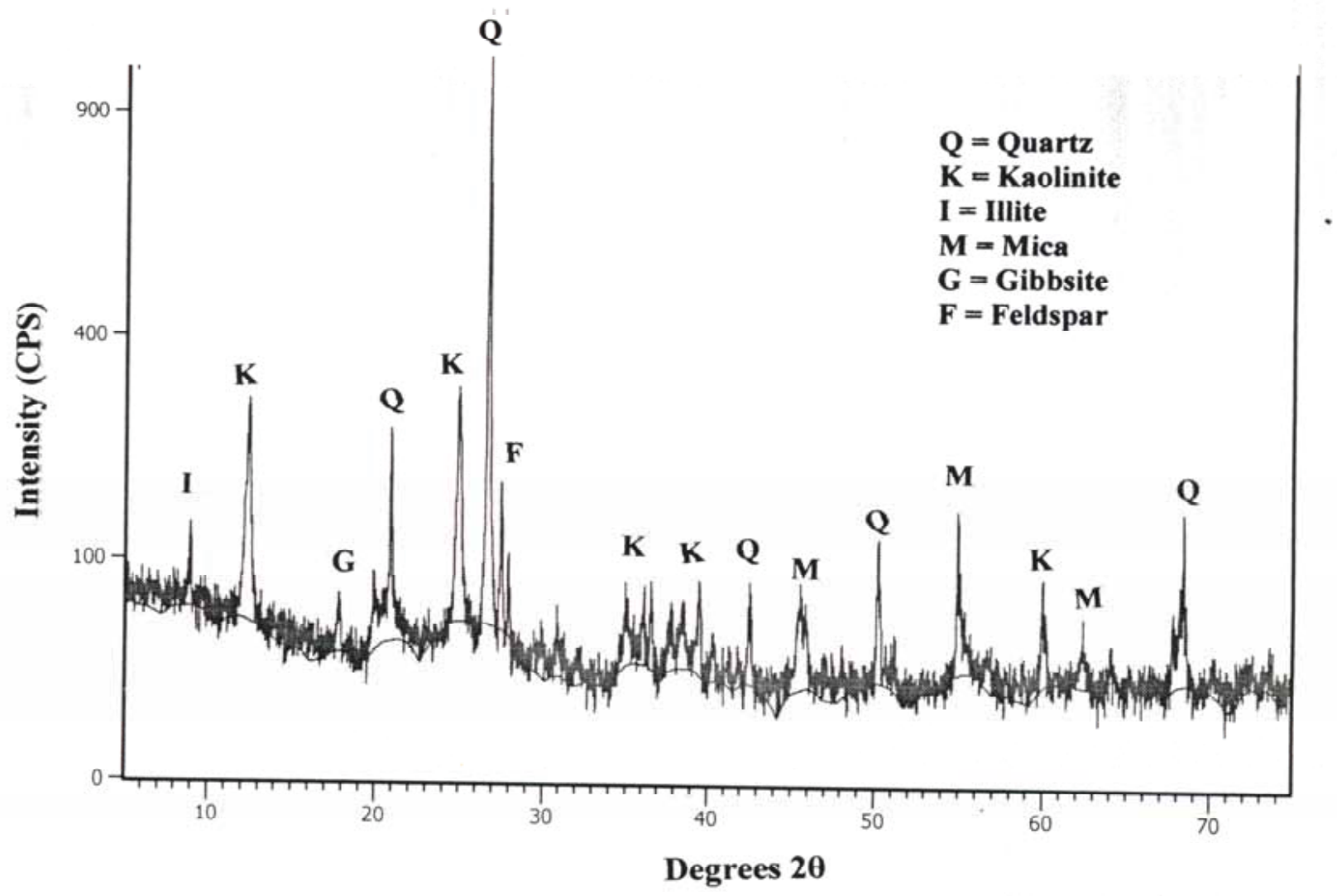

Fig. 5. XRD diffractogram of Hydgaon-2 (unwashed) 


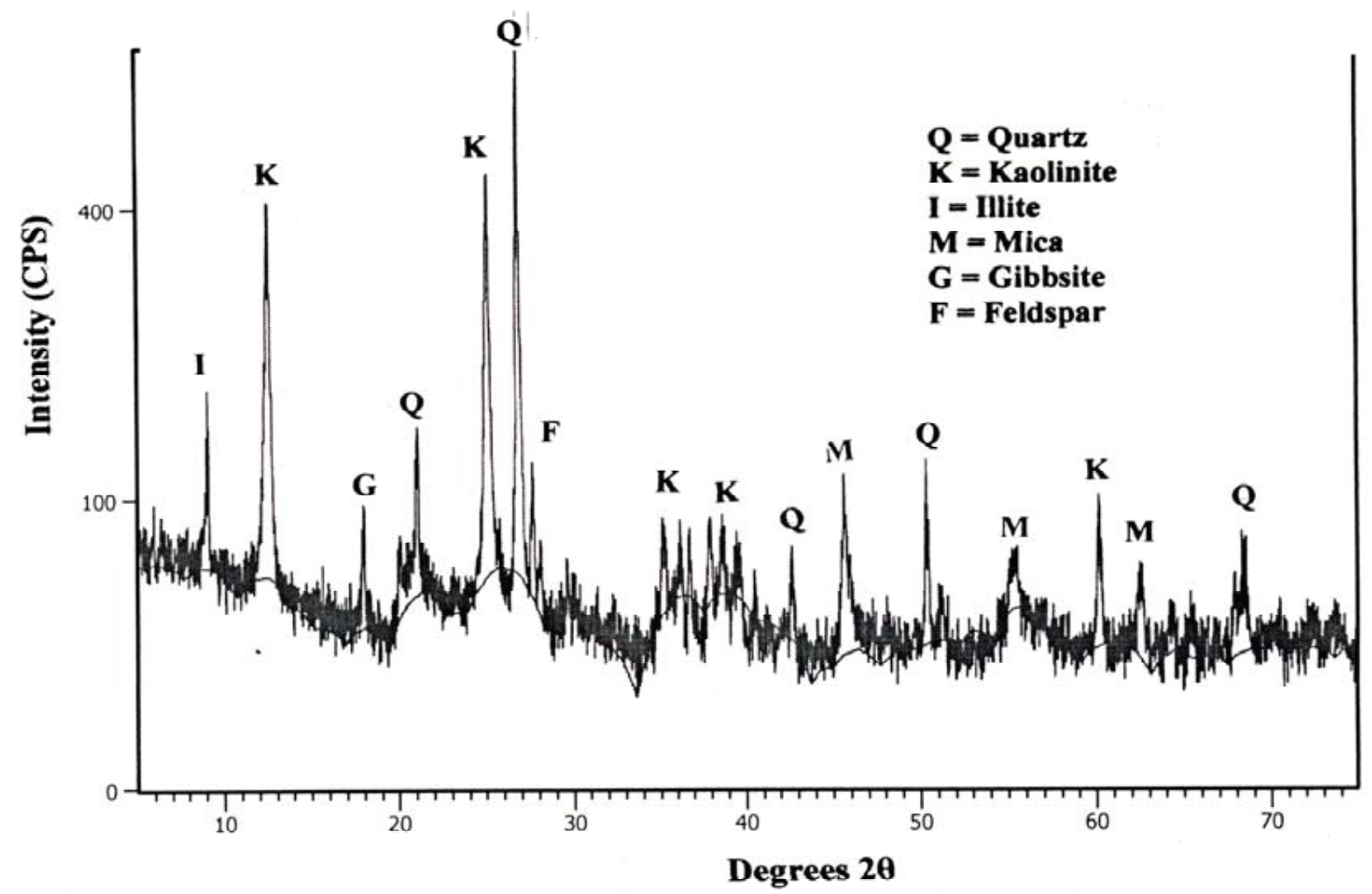

Fig. 6. XRD diffractogram of Hydgaon-2 (washed)

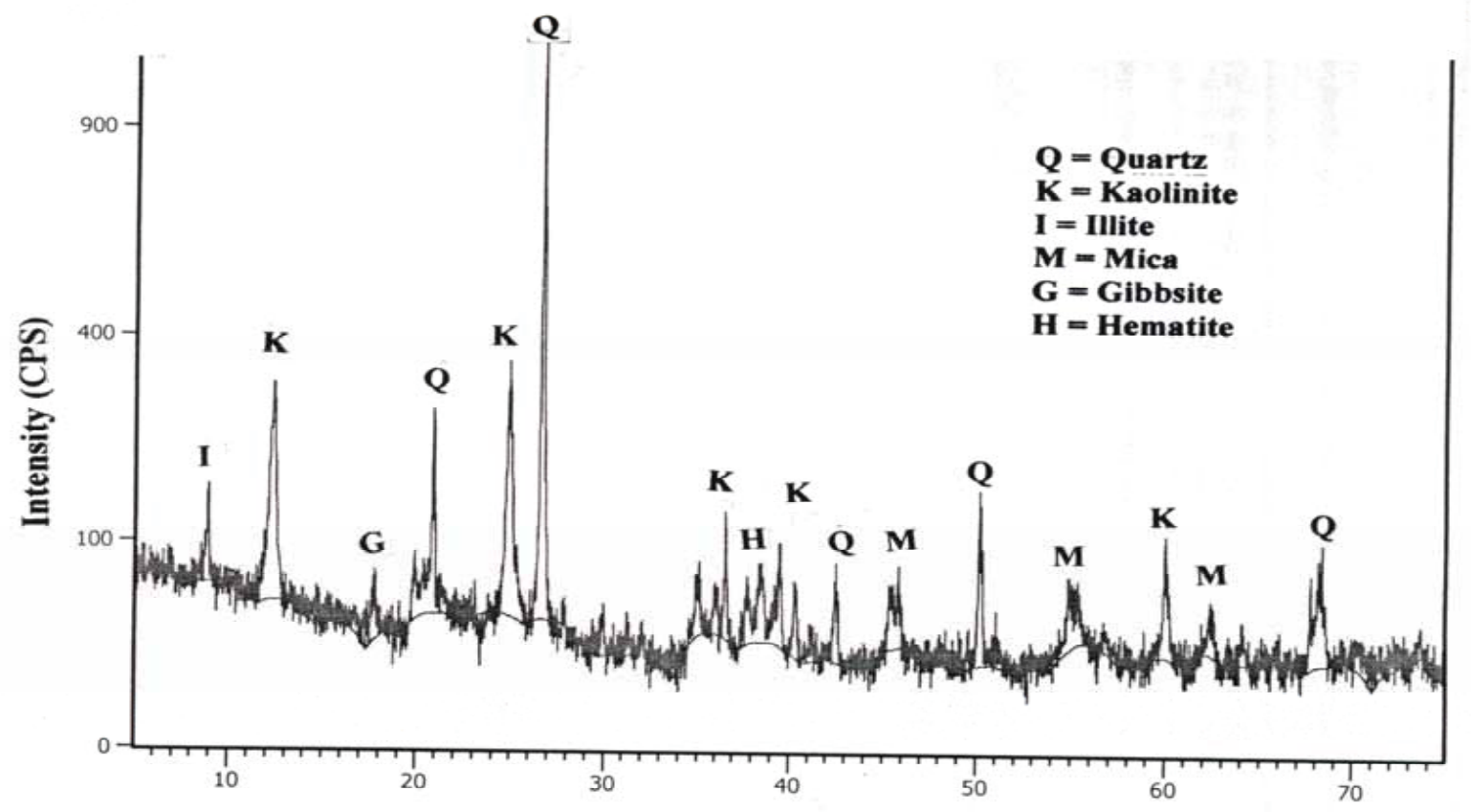

Degrees $2 \theta$

Fig. 7. XRD diffractogram of Kanchannagar (unwashed) 


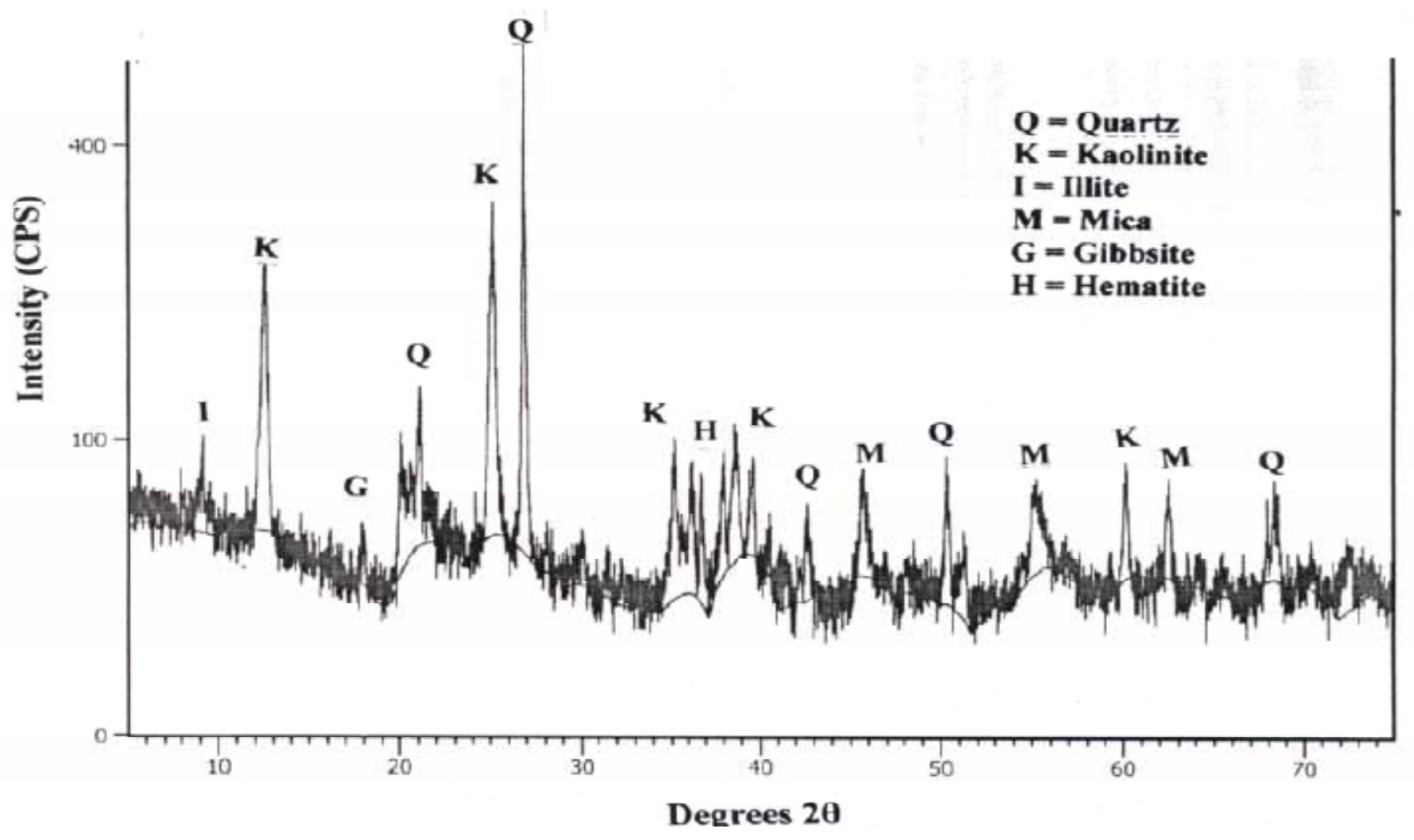

Fig. 8. XRD diffractogram of Kanchannagar (washed)

It can also be observed from Table IV that the Si-O stretching vibration bands at $428.20 \mathrm{~cm}^{-1}, 470.63 \mathrm{~cm}^{-1}, 538.14 \mathrm{~cm}^{-1}$, $694.37 \mathrm{~cm}^{-1}$ and $781.17 \mathrm{~cm}^{-1}$ indicate the presence of quartz (Si-O-Si) (Marel and Bentehspacher 1976). A vibration band observed at $914.92 \mathrm{~cm}^{-1}$ indicates the possibility of the presence of hematite (Gadsen 1975). A vibration band at $3441.01 \mathrm{~cm}^{-1}$ and a band at $1627.92 \mathrm{~cm}^{-1}$ in IR spectrum of these clay materials indicate the presence of water molecule (H-O-H). Bands at $3620.36 \mathrm{~cm}-1$ and $3693.23 \mathrm{~cm}-1$ show the presence of inter layer hydrogen bonding (Al--O-H) in clay. Most of the bands such as $470.43 \mathrm{~cm}-1,538.14 \mathrm{~cm}-1,694.37$ $\mathrm{cm}^{-1}, 781.17 \mathrm{~cm}-1,914.26 \mathrm{~cm}-1,1031.4 \mathrm{~cm}^{-1}, 3441.01 \mathrm{~cm}^{-1}$, $3620.36 \mathrm{~cm}^{-1}$ and $3693.64 \mathrm{~cm}^{-1}$ indicate the presence of kaolinite (Tuddenhan and Lyon 1960) in clay. The presence of bands in three different types Patia clay (unwashed and washed) at $3620.36 \mathrm{~cm}^{-1}, 3693.60 \mathrm{~cm}^{-1}, 3441.01 \mathrm{~cm}^{-1}$, $1627.92 \mathrm{~cm}^{-1}, 1031.40 \mathrm{~cm}^{-1}, 914.26 \mathrm{~cm}^{-1}, 781.17 \mathrm{~cm}^{-1}$ and $428.20 \mathrm{~cm}^{-1}$ show the presence of illite and mica (Wolf 1963).

Hydgaon-2 contains higher amount illite, kaolinite and gibbsite phases than Hydgaon-1 and Kanchannagar. The Hydgaon-2 has also the higher LOI because of the presence of high gibbsite and organic materials and lower amount of silica.

Table IV. FTIR bands of Patia clay (unwashed and washed) along with their possible assignments

\begin{tabular}{|c|c|c|}
\hline$\overline{B a n d s ~(c m-1) ~}$ & Assignments & \\
\hline 3693.64 & & Al--O-H str. \\
\hline 3620.36 & & $\mathrm{Al}-\mathrm{O}-\mathrm{H}$ (inter linkage) \\
\hline 3441.01 & & $\mathrm{H}-\mathrm{O}-\mathrm{H}$ str. \\
\hline 1627.92 & & $\mathrm{H}-\mathrm{O}-\mathrm{H}$ str. \\
\hline 1031.4 & & Si-O-Si str. \\
\hline 914.26 & & Al--O-H \\
\hline 781.17 & & $\mathrm{Si}-\mathrm{O}$ str. \\
\hline 694.37 & & $\mathrm{Si}-\mathrm{O}-\mathrm{Al}$ str. \\
\hline 538.14 & & $\mathrm{Si}-\mathrm{O}$ str. Si-O-Al str. \\
\hline 470.63 and & 428.20 & Si-O-Fe str. \\
\hline
\end{tabular}




\section{Conclusion}

From XRD, FTIR and chemical analysis of three types of Patia clay, it is concluded that Patia clay from three different areas contain silica and alumina as major constituents and iron, calcium, potassium and magnesium oxide are present as minor quantities. The loss on ignition values are higher in washed clay with respective to unwashed clay due to the presence of gibbsite. The plasticity of washed clay are the higher comparable to unwashed clay. The water absorption values decrease and the firing shrinkage values increase with increasing firing temperature which indicate that the vitrification characteristics is improved in washed clay with respect to unwashed clays. The kaolinite, quartz and illite are present as major phases in Patia clay of three different areas. From various properties and microstructure observations, it is apparent that Patia clay may be used as a impotant ceramic raw material in ceramic industries in Bangladesh to produce various ceramic products like tableware, tiles etc and has the prospect to lower the dependency of imported clay materials. Hydgaon-2 appears to be the best in quality among three types of Patia clay.

\section{References}

Adnan M., Hossain S. M., Fakhrul I. Md., Potential of locally available clay as raw materials for traditional-ceramic manufacturing industries, J. Chem. Eng., IEB, Che., 26: 2011

Alim B. M. and Shamin J. A. (1964), Investigations of some clays of East Pakistan, J. East Regional Lab. P.C.S.I.R., 1:

Bender W., Handle F., Brick and Tile making: Procedure and operation practice in the heavy clay industries, Bauverlag Gmbh, Wiesbaden and Berlin 1982

Gadsen J A, Infrared spectra of minerals and related inorganic compounds (London: Butterworths), (1975), Galos K., Ceramic International, 237: 851-861, 2011

Huber J. M., "Kalolin clays and their industrial uses", Corporation, 100 Park Ave., N.Y. 17, U.S.A., 1956

Klinefelter T. A., Meyer W.W. and Vachuska E. J., J. Am. Ceram. Soc., 16: 269, 1933

Klinefelter T. A. and Meyer W.W., ibid, 18: 163, 1935
Lee V-G., Yeh T-H., Materials Sci. and Eng.: A 485: 5-13, 2008

Mahmoudi S., Srasra E., Zargoune F., Applied Clay Science, 42: 125-129, 2008

Malaiskiene, J., Maciulaitis S. R., Kicaite A., Construction and Building Materials, 25: 3168-3174, 2011

Marel H. M. V. and Bentehspacher H, Atlas of infrared spectroscopy of clay minerals and their admixtures (Elsevier Science Publishers), 1976

Misra M.L and Hummel F.A., Bull. Amer. Ceram. Soc., 28: 235, 1949

Namara, E. P. M. and Dulberg, I. "Fundamentals of Ceramics", 2nd Edn., College of Mineral Industries, The Pennsylvania State University, Pa., U.S.A., p. 72, 1958

Ngun B.K., Mohamad H., Sulaiman S.K., Sulaiman M.Y.M., Isobe T., Okada K., and Ahmad Z.A., (2012) Changes in physical, chemical, and microstructure and strength relationships of some combodian clays, J. Ceram. Proc. Res., 13: 547- 555.

Ralph E. Grim, Clay Mineralogy (New York; McGraw Hill Book Co., 1968

Rolad and Joseph Clark, J. Am. Ceram. Soc., 10: 98, 1927

Stull R. T. and Bole, G. A., J. Am. Ceram. Soc., 6: 730, 1923

Tamjid. G., "Effect of composition and firing cycle on the properties of high tension ceramic insulator", M.Sc. thesis, MME, BUET, 2004

Tuddenhan W. M. and Lyon R. J. P., Anal. Chem., 32: 1630, 1960

Wolf R. G., American Mineralogist, 48: 390, 1963

Received: 16 January 2014; Revised: 1 September 2014; Accepted: 22 December 2014. 